\title{
Population vulnerability to COVID-19 in Europe: a burden of disease analysis
}

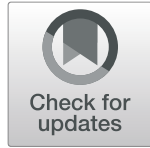

Grant M. A. Wyper ${ }^{1 *}$ (D, Ricardo Assunção ${ }^{2}$, Sarah Cuschieri ${ }^{3}$, Brecht Devleesschauwer ${ }^{4,5}$, Eilidh Fletcher ${ }^{6}$, Juanita A. Haagsma7, Henk B. M. Hilderink ${ }^{8}$, Jane Idavain ${ }^{9}$, Tina Lesnik ${ }^{10}$, Elena Von der Lippe ${ }^{11}$, Marek Majdan ${ }^{12}$, Milena S. Milicevic ${ }^{13}$, Elena Pallari ${ }^{14}$, José L. Peñalvo ${ }^{15}$, Sara M. Pires ${ }^{16}$, Dietrich Plaß37, João V. Santos ${ }^{18,19,20}$, Diane L. Stockton ${ }^{1}$, Sofie Theresa Thomsen ${ }^{16}$ and lan Grant ${ }^{6}$

\begin{abstract}
Background: Evidence has emerged showing that elderly people and those with pre-existing chronic health conditions may be at higher risk of developing severe health consequences from COVID-19. In Europe, this is of particular relevance with ageing populations living with non-communicable diseases, multi-morbidity and frailty. Published estimates of Years Lived with Disability (YLD) from the Global Burden of Disease (GBD) study help to characterise the extent of these effects. Our aim was to identify the countries across Europe that have populations at highest risk from COVID-19 by using estimates of population age structure and YLD for health conditions linked to severe illness from COVID-19.
\end{abstract}

Methods: Population and YLD estimates from GBD 2017 were extracted for 45 countries in Europe. YLD was restricted to a list of specific health conditions associated with being at risk of developing severe consequences from COVID-19 based on guidance from the United Kingdom Government. This guidance also identified individuals aged 70 years and above as being at higher risk of developing severe health consequences. Study outcomes were defined as: (i) proportion of population aged 70 years and above; and (ii) rate of YLD for COVID-19 vulnerable health conditions across all ages. Bivariate groupings were established for each outcome and combined to establish overall population-level vulnerability.

Results: Countries with the highest proportions of elderly residents were Italy, Greece, Germany, Portugal and Finland. When assessments of population-level YLD rates for COVID-19 vulnerable health conditions were made, the highest rates were observed for Bulgaria, Czechia, Croatia, Hungary and Bosnia and Herzegovina. A bivariate analysis indicated that the countries at high-risk across both measures of vulnerability were: Bulgaria; Portugal; Latvia; Lithuania; Greece; Germany; Estonia; and Sweden.

(Continued on next page)

\footnotetext{
*Correspondence: gwyper@nhs.net

'Place and Wellbeing Directorate, Public Health Scotland, Glasgow, Scotland,

UK

Full list of author information is available at the end of the article
}

O The Author(s). 2020, corrected publication [2020]. Open Access This article is licensed under a Creative Commons Attribution 4.0 International License, which permits use, sharing, adaptation, distribution and reproduction in any medium or format, as long as you give appropriate credit to the original author(s) and the source, provide a link to the Creative Commons licence, and indicate if changes were made. The images or other third party material in this article are included in the article's Creative Commons licence, unless indicated otherwise in a credit line to the material. If material is not included in the article's Creative Commons licence and your intended use is not permitted by statutory regulation or exceeds the permitted use, you will need to obtain permission directly from the copyright holder. To view a copy of this licence, visit http://creativecommons.org/licenses/by/4.0/. The Creative Commons Public Domain Dedication waiver (http:// creativecommons.org/publicdomain/zero/1.0/) applies to the data made available in this article, unless otherwise stated in a credit line to the data. 
(Continued from previous page)

Conclusion: Routine estimates of population structures and non-fatal burden of disease measures can be usefully combined to create composite indicators of vulnerability for rapid assessments, in this case to severe health consequences from COVID-19. Countries with available results for sub-national regions within their country, or national burden of disease studies that also use sub-national levels for burden quantifications, should consider using non-fatal burden of disease estimates to estimate geographical vulnerability to COVID-19.

Keywords: COVID-19, Coronavirus, Burden of disease, DALY, YLD, Summary measures of population health, GBD, Vulnerability, European burden of disease network

\section{Background}

In burden of disease studies, estimates of disabilityadjusted life years (DALYs) are commonly used to assess the leading causes of burden amongst populations [1]. DALYs are composed of estimates of population health loss due to living with the consequences of morbidity and premature mortality. Years Lived with Disability (YLD) capture the morbidity (both the prevalence and severity of the disease) component of DALYs by estimating the number of years lost due to conditions diminishing the overall health status, and are a useful indicator to assess how impaired populations are due to living with the consequences of disease and injury [2].

Internationally, countries have reacted to the COVID-19 outbreak by introducing key public health nonpharmaceutical interventions (otherwise known as physical, or social, distancing) to protect vulnerable population groups [3]. Evidence has emerged to show that elderly people and those with pre-existing multi-morbid conditions may be at higher risk of developing severe health consequences from COVID-19 [4]. In Europe, 31\% of the population are estimated to have a condition that is on the Government of the United Kingdom's (UK) list of conditions at increased risk of severe health consequences from COVID-19 disease [5]. There is currently a disparity of comparable information across countries to objectively assess country-level vulnerability to COVID-19. However, there is a wealth of data on population structure, health status and causes of health loss in countries, which can be obtained from the Global Burden of Disease (GBD) study [6]. These data can be used to approximate how vulnerable populations are, particularly by focusing on the population share of elderly residents and the YLD for health conditions that have been identified as potentially linked to severe illness from COVID-19. This is of particular relevance for European countries, as increases in lifespan have resulted in increasingly ageing populations living with effects of non-communicable diseases, multimorbidity and frailty [7].

The aim of this study was to identify the countries across Europe that have populations at highest risk for severe disease progression after COVID-19 infection by using estimates of population structure and YLD for health conditions linked to severe illness from COVID19. This study was carried out using data from GBD 2017 for the reference year 2017, considering two measures of vulnerability: (i) rate of elderly population; and (ii) rate of YLD for health conditions identified at risk of severe health consequences from COVID-19.

\section{Methods \\ Data}

The GBD Results Tool [8] was used to extract Years Lived with Disability (YLD) estimates for both sexes, age-groups (all ages; 70 years and above; and 80 years and above) and GBD 2017 level 3 cause [9] for each country defined as residing in Central, Eastern and Western Europe ( $N=45$ countries). Estimates were considered for the constituent nations of the United Kingdom (UK): England; Northern Ireland; Scotland; and Wales, rather than the UK as a whole. In this study, hereafter, the elderly population denotes the age-group 70 years and above.

Data were retained for specific causes based on guidance from the UK Government (as at 30th March 2020) on those health conditions that indicated a risk of severe health consequences from COVID-19 [10]. Two groups were defined: individuals aged 70 years and above, and those under 70 years that have one or more pre-existing underlying health condition. The guidance provided by the UK Government is outlined in the Supplementary Appendix and the list of pre-existing conditions were mapped to the GBD 2017 cause list (Table 1).

Some emerging evidence has considered obesity and hypertension as independent risk factors for severe health consequences from COVID-19 [11, 12]. However, we do not consider them separately in this study as the vast majority of disease outcomes associated with these risk factors are included in the mapping to the GBD cause list (Table 1). For hypertension, all disease outcomes linked to the high systolic blood pressure risk factor are included (cardiovascular diseases and chronic kidney disease in Table 1). In addition, GBD include separate estimates for hypertensive disease and these are included within cardiovascular diseases. The disease outcomes associated with obesity are also all covered in 
Table 1 Mapping of UK Government guidance on pre-existing medical conditions at risk of severe illness from COVID-19 to the GBD 2017 cause list

\begin{tabular}{|c|c|}
\hline Pre-existing health condition(s) & GBD mapped cause(s) \\
\hline All health conditions & All-causes \\
\hline \multirow[t]{5}{*}{ Chronic respiratory diseases } & $\begin{array}{l}\text { Chronic obstructive pulmonary } \\
\text { disease }\end{array}$ \\
\hline & Pneumoconiosis \\
\hline & Asthma \\
\hline & $\begin{array}{l}\text { Interstitial lung disease and } \\
\text { pulmonary sarcoidosis }\end{array}$ \\
\hline & Other chronic respiratory diseases \\
\hline Chronic heart disease & $\begin{array}{l}\text { Cardiovascular diseases (chronic and } \\
\text { acute) }\end{array}$ \\
\hline Chronic kidney disease & Chronic kidney disease \\
\hline Chronic liver disease & $\begin{array}{l}\text { Cirrhosis and other chronic liver } \\
\text { diseases }\end{array}$ \\
\hline \multirow[t]{6}{*}{ Chronic neurological conditions } & $\begin{array}{l}\text { Alzheimer's disease and other } \\
\text { dementias }\end{array}$ \\
\hline & Parkinson's disease \\
\hline & Epilepsy \\
\hline & Multiple sclerosis \\
\hline & Motor neuron disease \\
\hline & Other neurological disorders \\
\hline Diabetes & Diabetes mellitus \\
\hline \multirow[t]{2}{*}{ Problems with spleen } & Sickle cell disorders \\
\hline & Sickle cell trait \\
\hline $\begin{array}{l}\text { Cancer undergoing active } \\
\text { chemotherapy or radiotherapy }\end{array}$ & All cancer types \\
\hline \multicolumn{2}{|l|}{$\begin{array}{l}\text { Cancers of the blood or bone } \\
\text { marrow }\end{array}$} \\
\hline Seriously overweight & $\begin{array}{l}\text { Covered in mapping for chronic } \\
\text { respiratory diseases, cardiovascular } \\
\text { diseases, chronic kidney disease, } \\
\text { cirrhosis and chronic liver diseases, } \\
\text { and diabetes }\end{array}$ \\
\hline $\begin{array}{l}\text { Severe chest conditions such as } \\
\text { cystic fibrosis or severe asthma }\end{array}$ & $\begin{array}{l}\text { Covered in mapping for chronic } \\
\text { respiratory diseases }\end{array}$ \\
\hline $\begin{array}{l}\text { Organ transplant and remain on } \\
\text { ongoing immunosuppression } \\
\text { medication }\end{array}$ & $\begin{array}{l}\text { Covered in mapping for chronic } \\
\text { kidney disease }\end{array}$ \\
\hline Severe disease of body systems & $\begin{array}{l}\text { Covered in mapping from all pre- } \\
\text { existing health conditions }\end{array}$ \\
\hline Those who are pregnant & Not covered \\
\hline
\end{tabular}

the mapping to the GBD cause list with the exception of Gout. Gout accounted for only 0.2\% (95\% uncertainty interval: $0.15-0.25 \%$ ) of total YLD in GBD European Region in 2017 [8].

A permalink to the GBD Results Tool [8] query that were used to generate the data used in this study are outlined in the Data Availability section. Additionally, data on the total 2017 resident populations and population aged 70 years and above for each country were sourced from the Global Health Data Exchange (GHDx) [13]. These population denominators were used in the production of GBD 2017 estimates.

\section{Analyses}

Descriptive summaries were calculated for the proportion of elderly population, and YLD for COVID-19 vulnerable health conditions were described using crude rates per 100,000 population. The numerators for the population proportion calculations were based on elderly populations, whereas the YLD rate calculation numerators were based on population totals. Denominators were based on the all ages population data sourced from GHDx [13].

Each measure was divided into tertiles (three binned categories: low; mid; and high). These categories were calculated to determine three equal size groups of vulnerability. Bivariate groupings were established by considering the overlapping of the measures and were depicted in a scatter plot to identify groups of countries, both in terms of the proportion of elderly population and the rate of YLD for conditions associated with worse COVID-19 prognosis. Spearman's rank correlation coefficient $(\rho)$ was used to describe the correlation between the percentage of elderly population and the rate of YLD for COVID-19 vulnerable health conditions.

\section{Results}

\section{Proportions of elderly population by country}

The five countries with the highest proportions of elderly residents (aged 70 years and above) were: Italy (16.4\%); Greece (16.2\%); Germany (15.4\%); Portugal (15.3\%); and Finland (14.7\%) (Table 2). Conversely, the countries with the lowest proportions of elderly population were Israel (7.7\%); Moldova (8.2\%); Russian Federation (8.8\%); Macedonia (8.8\%); and Albania (9.1\%). The ratio of the country with the highest (Italy) and lowest (Israel) proportion of elderly residents was 2.14 , indicating over a two-fold difference between the countries.

When looking at stratified differences within the elderly age-group, the five countries with the highest percentage of population aged 80 years and above were: France (44.5\%); Spain (44.4\%); Greece (43.2\%); Belgium (42.2\%) and Italy (41.7\%). The five countries with the lowest percentage of population aged 80 years and above were: Albania (30.8\%); Bosnia and Herzegovina (31.4\%); Czechia (31.5\%); Macedonia (32.4\%); and Montenegro (32.5\%). Between the country with the highest (France) percentage of population aged 80 years and above and lowest (Albania), there was an absolute difference of $13.7 \%$. 
Table 2 Summary of percentage of elderly population and YLD rates for COVID-19 vulnerable health conditions, by country, 2017

\begin{tabular}{|c|c|c|c|c|c|}
\hline \multirow[b]{2}{*}{ Country } & \multicolumn{2}{|c|}{$\%$ of elderly population } & \multicolumn{3}{|c|}{$\begin{array}{l}\text { YLD rate for COVID-19 vulnerable } \\
\text { health conditions }\end{array}$} \\
\hline & $\begin{array}{c}70 \text { years old and } \\
\text { above }\end{array}$ & $\begin{array}{c}80 \text { years and above } \\
\text { (of those aged } 70 \text { years } \\
\text { and above) }\end{array}$ & All ages & $\begin{array}{l}\text { Under } 70 \\
\text { years }\end{array}$ & $\begin{array}{l}70 \text { years } \\
\text { and above }\end{array}$ \\
\hline Italy & 16.4 & 41.7 & 2,951 & 1,645 & 9,631 \\
\hline Greece & 16.2 & 43.2 & 3,211 & 1,845 & 10,289 \\
\hline Germany & 15.4 & 39.3 & 3,180 & 1,874 & 10,347 \\
\hline Portugal & 15.3 & 40.2 & 3,466 & 2,202 & 10,487 \\
\hline Finland & 14.7 & 36.4 & 3,123 & 1,954 & 9,927 \\
\hline Sweden & 14.4 & 35.5 & 3,170 & 1,913 & 10,634 \\
\hline Latvia & 14.3 & 36.5 & 3,370 & 2,077 & 11,132 \\
\hline Bulgaria & 14.3 & 33.8 & 3,760 & 2,398 & 11,944 \\
\hline Wales & 14.3 & 36.6 & 3,041 & 1,893 & 9,944 \\
\hline Lithuania & 14.0 & 39.0 & 3,321 & 2,037 & 11,194 \\
\hline Spain & 13.8 & 44.4 & 2,628 & 1,547 & 9,368 \\
\hline Estonia & 13.6 & 38.8 & 3,175 & 1,973 & 10,817 \\
\hline France & 13.5 & 44.5 & 2,505 & 1,492 & 9,004 \\
\hline Austria & 13.4 & 36.9 & 2,848 & 1,722 & 10,104 \\
\hline Malta & 13.4 & 33.0 & 3,166 & 2,078 & 10,186 \\
\hline Croatia & 13.4 & 36.5 & 3,651 & 2,333 & 12,199 \\
\hline Denmark & 13.3 & 32.7 & 3,034 & 1,956 & 10,060 \\
\hline Belgium & 13.1 & 42.2 & 3,073 & 1,909 & 10,774 \\
\hline Switzerland & 13.1 & 38.7 & 2,684 & 1,664 & 9,462 \\
\hline Slovenia & 13.1 & 39.4 & 3,248 & 2,062 & 11,145 \\
\hline Scotland & 12.8 & 36.4 & 3,068 & 2,025 & 10,157 \\
\hline Czechia & 12.8 & 31.5 & 3,690 & 2,401 & 12,470 \\
\hline Hungary & 12.8 & 35.1 & 3,613 & 2,356 & 12,182 \\
\hline Netherlands & 12.6 & 35.7 & 3,022 & 1,971 & 10,321 \\
\hline England & 12.4 & 37.9 & 2,895 & 1,869 & 10,145 \\
\hline Romania & 12.2 & 36.9 & 3,293 & 2,139 & 11,616 \\
\hline Norway & 11.4 & 36.8 & 2,768 & 1,789 & 10,362 \\
\hline Serbia & 11.1 & 33.0 & 3,411 & 2,268 & 12,598 \\
\hline Northern Ireland & 11.1 & 36.2 & 2,734 & 1,810 & 10,163 \\
\hline Poland & 10.7 & 39.6 & 3,131 & 2,126 & 11,554 \\
\hline Ukraine & 10.5 & 35.6 & 2,867 & 2,000 & 10,260 \\
\hline $\begin{array}{l}\text { Bosnia and } \\
\text { Herzegovina }\end{array}$ & 10.1 & 31.4 & 3,553 & 2,498 & 12,901 \\
\hline Luxembourg & 9.9 & 39.7 & 2,996 & 2,061 & 11,478 \\
\hline Andorra & 9.8 & 40.6 & 2,548 & 1,745 & 9,954 \\
\hline Slovakia & 9.6 & 32.8 & 3,060 & 2,124 & 11,854 \\
\hline Iceland & 9.6 & 39.3 & 2,665 & 1,831 & 10,537 \\
\hline Belarus & 9.5 & 39.5 & 2,689 & 1,879 & 10,371 \\
\hline Cyprus & 9.2 & 32.9 & 2,272 & 1,536 & 9,524 \\
\hline Montenegro & 9.2 & 32.5 & 2,978 & 2,078 & 11,862 \\
\hline Ireland & 9.2 & 34.7 & 2,588 & 1,802 & 10,387 \\
\hline Albania & 9.1 & 30.8 & 2,460 & 1,701 & 10,024 \\
\hline Macedonia & 8.8 & 32.4 & 3,009 & 2,159 & 11,807 \\
\hline $\begin{array}{l}\text { Russian } \\
\text { Federation }\end{array}$ & 8.8 & 37.3 & 2,616 & 1,840 & 10,695 \\
\hline Moldova & 8.2 & 35.9 & 2,448 & 1,827 & 9,373 \\
\hline Israel & 7,7 & 37.8 & 1,870 & 1,260 & 9,229 \\
\hline
\end{tabular}

Country order is based on the descending proportion of elderly residents. Cells shaded in orange represent the highest values within each metric, with cells shaded in green representing the lowest value

Rate of YLD for COVID-19 vulnerable health conditions When the rate of YLD for health conditions associated with higher COVID-19 vulnerability was assessed for all ages, the five countries with the highest rates per 100, 000 population were: Bulgaria (3760); Czechia (3690); Croatia (3651), Hungary (3613); and Bosnia and
Herzegovina (3553) (Table 2). The five countries with the lowest rates were: Israel (1870); Cyprus (2272); Moldova (2448); Albania (2460); and France (2505). There was a rate ratio of 2.01 between the country with the highest rate (Bulgaria) and the country with the lowest rate (Israel). 
Insights into rates of YLD for health conditions indicating higher COVID-19 vulnerability for those under 70 years and elderly residents were that there were four countries that were common amongst the leading five countries in both age-groups. These countries were: Czechia, Croatia, Hungary and Bosnia and Herzegovina. Of the five countries with the lowest rates in the under 70 years and elderly age-groups, there were three countries that were common: Israel, France and Spain.

\section{Summary of combined vulnerability}

There was a moderate association $(\rho=0.54)$ between the percentage of elderly population and the rate of YLD for COVID-19 vulnerable health conditions. A bivariate analysis indicated that the countries which had high proportions of elderly population and high rates of YLD for COVID-19 vulnerable health conditions were: Bulgaria; Portugal; Latvia; Lithuania; Greece; Germany; Estonia; and Sweden. Conversely, the countries with the lowest proportions of elderly population and lowest rates of YLD for COVID-19 vulnerable health conditions were: Israel; Cyprus; Moldova; Albania; Andorra; Ireland; Russian Federation; Iceland; and Belarus. Bosnia and Herzegovina had a high rate of YLD for COVID-19 vulnerable health conditions, but a relatively low proportion of elderly population. On the other hand, Spain, France and Austria all had high proportions of elderly population but a relatively low rate of YLD for COVID-19 vulnerable health conditions (Fig. 1).

\section{Discussion}

\section{Summary of findings}

This study set out to establish which countries across Europe had populations that were most likely to be vulnerable to severe health consequences as a result of COVID-19 infection. This assessment was made using data on population age structure, and data on YLD for health conditions identified as increasing the risk of COVID-19 severity, the latter illustrating the extent to which populations are vulnerable through living with illhealth due to causes of disease.

Estimates of vulnerability to COVID-19 using elderly population share indicated that the countries with the highest proportions of elderly residents were Italy, Greece, Germany, Portugal and Finland. When assessments of population-level YLD rates for COVID-19 vulnerable health conditions were made the highest rates were observed for Bulgaria, Czechia, Croatia, Hungary and Bosnia and Herzegovina. Our bivariate analysis indicated that the countries which had high rates across both measures of vulnerability were: Bulgaria; Portugal; Latvia; Lithuania; Greece; Germany; Estonia; and Sweden.
Whilst these findings indicate population-level vulnerability due to health loss suffered, they do not take into account other important factors such as country and sub-national responses to the COVID-19 outbreak through public health non-pharmaceutical interventions. Neither do they take into account factors such as: population density, the capacity or ease of access to health and social care services and the disruption to existing services due to the COVID-19 crisis, all of which will have a significant impact on the extent to which vulnerable populations are adequately protected from harm. This may partly explain why countries identified in this analysis with high and low vulnerability to severe health consequences from COVID-19 do not always correspond with those countries in Europe with the highest and lowest case fatality ratios due to COVID-19 [14]. For example, within the Baltic states Latvia and Estonia have high vulnerability as measured on both indicators. However, Latvia responded to the crisis quickly by closing their borders and implementing restrictive measures much faster than Estonia, and case fatality rates are higher in Estonia [14-16]. This example highlights that a number of additional factors could contribute to differences between vulnerability and extent of adverse consequences, including: care identification and under-reporting, the speed at which countries introduced restrictive measures, and restrictions on air travel. The use of summary health indicator such as YLD to identify severe health consequences from COVID-19 infections should be regarded as just one of the elements that need to be taken into account in a complete risk assessment of vulnerability.

\section{Strengths and limitations}

The study was carried out using estimates from GBD 2017, which is a widely used and well-established mechanism that has methodological consistency when producing estimates for individual countries [6]. The use of GBD 2017 is advantageous as estimates are publically accessible, which allows for the rapid assessments of impact in response to public health emergency scenarios, such as the COVID-19 outbreak. Our findings are comparable on a like-for-like basis across countries. However, data sources that are fed into the modelling process for country-level estimates can vary based on location, therefore there is a risk that some of the differences which we observe may be attributed to the use, or omission, of high quality data sources [17]. We have opted not to include estimates of uncertainty in our estimates. Uncertainty intervals in the GBD study can often be wide, representing large degrees of uncertainty, so users of these results must bear in mind that these findings relate to the best available point-estimate. To retain 


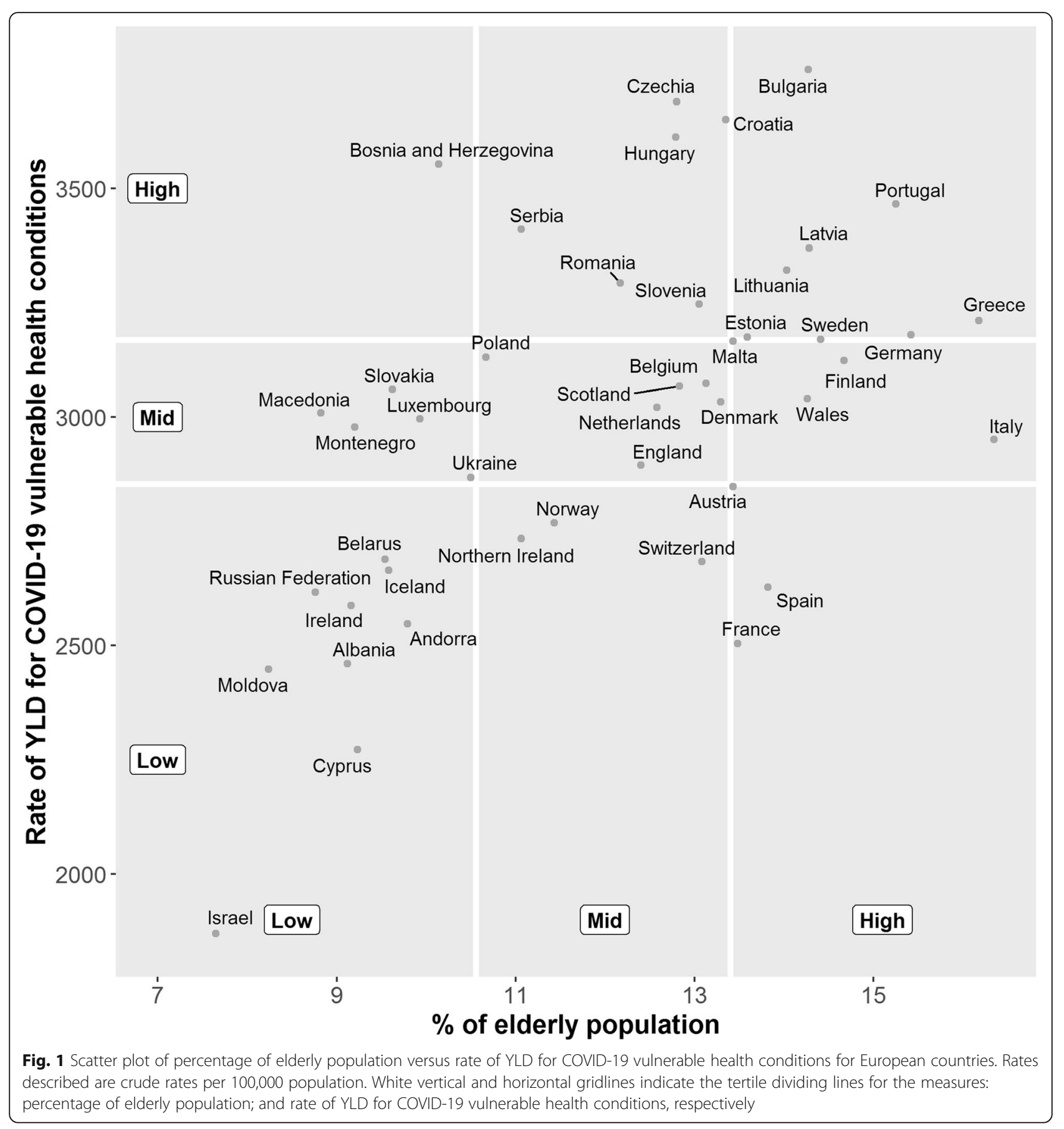

consistency with estimates of YLD from GBD 2017, data on population size and structure was obtained from GHDx [13] which may differ from nationally produced estimates.

Previous research has suggested that the assumption of fixed severity distributions across countries may be unreasonable [18]. In our study of COVID-19 related vulnerable conditions, we did not include some of the leading causes of YLD, such as major depressive disorders and substance use disorders, which are thought to be the most likely to be affected by this assumption. Thus, our COVID-19 vulnerable conditions analysis may be less affected by this assumption [19]. Additionally, our study has assumed that the extent of vulnerability to COVID-19 can be determined by disability weights. For example, on average a greater weight would be given to those suffering from chronic obstructive pulmonary disease than to ischaemic heart disease [20]. This assumption may be problematic if the risk of COVID-19 associated with each health condition is not 
representative of relative differences in disability weight between causes. Also, particular combinations of disease may result in higher risks of consequences of COVID19, while all combinations are in this approach assumed to have a similar effect.

We have used YLD as a proxy for the severity of the selected vulnerable health conditions as YLD includes a weighting of the severity of diseases stages i.e. a weighted prevalence. We have chosen to explore the aim of the YLD summary measure to combine all conditions, rather than examine the impact of individual causes. We acknowledge that using disease prevalence data from GHDx could add further insight into quantifying the disease specific implications of severe health consequences from COVID-19. However, since prevalence gives equal weighting to each condition, we did not consider prevalence as useful for summary analyses as YLD which allows a weighted sum of prevalence of different diseases. Further analysis has previously been carried out elsewhere to explore using prevalence to quantify the risk for severe health consequences from COVID-19 infection to enhance assessment of a health systems vulnerability to COVID-19 [5].

\section{Implications for policy and research}

Our findings have important implications for decisionmaking and for future research. In our assessment of vulnerability, we have highlighted the countries in Europe with populations that are elderly, and vulnerable as a result of reduced health due to certain health conditions. From a decision-making perspective, this effectively communicates how locations can be assessed on a relative scale of risk of severe illness due to COVID-19. Although, at time of this publication, many countries have now employed public health non-pharmaceutical interventions for over two months, there are still many uncertainties about the further evolution of the pandemic and the virus itself. Therefore, until an effective vaccination or treatment is available, our findings highlight which countries have populations that are at highest risk and therefore should be prioritising the shielding of vulnerable individuals. Doing so can alleviate the extent to which essential healthcare services are overwhelmed, which will also contribute to curtailing the indirect impact of COVID-19. Still, our results should not be used as rationale for countries to justify a relaxing of existing non-pharmaceutical interventions. The countries we identified as having indicators of low vulnerability should not be complacent, as doing so would have severe adverse consequences. Our findings also have important implications if there are positive breakthroughs in the development of a vaccine that is both safe and effective, as they highlight which countries may benefit from it the most.

As research begins to focus on the evaluation of the impact of public health non-pharmaceutical interventions, an important aspect will be to establish baseline measures of risk to severe illness of COVID-19. Our findings provide an opportunity for this, particularly when assessing the factors for success of these interventions in populations that were facing similar levels of population vulnerability.

\section{Conclusion}

Our findings have highlighted that routine data on population structure can be usefully extended by using estimates of YLD to consider how populations are impaired by living with the consequences of ill-health due to causes of disease and injury. Countries with available estimates for subnational regions within their country, or national burden of disease studies that also estimate at sub-national levels should consider using non-fatal burden of disease estimates to estimate geographical vulnerability to COVID-19.

\section{Supplementary information}

Supplementary information accompanies this paper at https://doi.org/10. 1186/s13690-020-00433-y.

Additional file 1. Guidance on social distancing from the United Kingdom Government.

\section{Abbreviations}

COVID-19: Coronavirus Disease 2019; DALYs: Disability-Adjusted Life Years; GBD: Global Burden of Disease; GHDx: Global Health Data Exchange; UK: United Kingdom; YLD: Years Lived with Disability

\section{Acknowledgements}

We would like to acknowledge the GBD 2017 study investigators and collaborators, as without this study and their resulting estimates of population and YLD our study would not have been possible. We would also like to thank COST (European Cooperation in Science and Technology, https://www.cost.eu), as this study was conducted within the framework of COST Action CA18218 (European Burden of Disease Network).

\section{Authors' contributions}

GW and IG generated the initial idea for the study. GW carried out all analyses and visualisation of the results. GW drafted the manuscript with assistance from IG. IG coordinated and made edits to the manuscript based on responses from co-authors with assistance from GW. All other authors provided critical input into the interpretation of the results, revisions to the manuscript and approved the final draft.

\section{Funding}

This research received no specific grant from any funding agency in the public, commercial or not-for-profit sectors. Journal open access publications fees upon acceptance of this article in a peer-reviewed journal will be reimbursed under the COST action CA18218 (European Burden of Disease Network).

\section{Availability of data and materials}

The datasets used in this research study are all publically available. The permalink to data query used to obtain estimates of YLD is: http://ghdx. healthdata.org/gbd-results-tool?params=gbd-api-2017-permalink/376 d9a9ad8401f49f104650fab0b9305. 
Ethics approval and consent to participate

Not applicable.

\section{Consent for publication}

Not applicable.

\section{Competing interests}

All other authors declare that they have no competing interests.

\section{Author details}

${ }^{1}$ Place and Wellbeing Directorate, Public Health Scotland, Glasgow, Scotland, UK. ${ }^{2}$ Food and Nutrition Department, National Institute of Health Dr. Ricardo Jorge, Lisbon, Portugal. ${ }^{3}$ Department of Anatomy, Faculty of Medicine and Surgery, University of Malta, Msida, Malta. ${ }^{4}$ Department of Epidemiology and Public Health, Sciensano, Brussels, Belgium. ${ }^{5}$ Department of Veterinary Public Health and Food Safety, Ghent University, Merelbeke, Belgium. 'Data Driven Innovation Directorate, Public Health Scotland, Edinburgh, Scotland, UK. ${ }^{7}$ Department of Public Health, Erasmus MC University Medical Center, Rotterdam, The Netherlands. ${ }^{8}$ National Institute for Public Health and the Environment (RIVM), Bilthoven, The Netherlands. ${ }^{9}$ National Institute for Health Development, Tallinn, Estonia. ${ }^{10}$ National Institute of Public Health, Ljubljana, Slovenia. ${ }^{11}$ Department of Epidemiology and Health Monitoring, Robert Koch Institute, Berlin, Germany. ${ }^{12}$ Department of Public Health, Institute for Global Health and Epidemiology, Faculty of Health Sciences and Social Work, Trnava University, Trnava, Slovakia. ${ }^{13}$ Faculty of Medicine University of Belgrade, Belgrade, Serbia. ${ }^{14} \mathrm{MRC}$ Clinical Trials and Methodology Unit, University College London, London, UK. ${ }^{15}$ Unit of Noncommunicable Diseases, Department of Public Health, Institute of Tropical Medicine, Antwerp, Belgium. ${ }^{16}$ National Food Institute, Technical University of Denmark, Lyngby, Denmark. ${ }^{17}$ Exposure Assessment and Environmental Health Indicators, German Environment Agency, Berlin, Germany. ${ }^{18}$ MEDCIDS, Department of Community Medicine, Information and Health Decision Sciences, Faculty of Medicine, University of Porto, Porto, Portugal. ${ }^{19}$ CINTESIS, Centre for Health Technology and Services Research, Porto, Portugal. ${ }^{20}$ Public Health Unit, ACES Grande Porto VIII - Espinho/Gaia, ARS Norte, Porto, Portugal.

Received: 4 May 2020 Accepted: 19 May 2020

Published online: 29 May 2020

\section{References}

1. Murray CJL, Lopez AD. The global burden of disease: a comprehensive assessment of mortality and disability from diseases, injuries and risk factors in 1990 and projected to 2020. Cambridge: Harvard University Press on behalf of the World Health Organization and the World Bank; 1996.

2. Klijs B, Nusselder WJ, Looman CW, Mackenbach JP. Contribution of chronic disease to the burden of disability. PLoS One. 2011;6(9):e25325 https://doi. org/10.1371/journal.pone.0025325.

3. Ebrahim SH, Ahmed QA, Gozzer E, Schlagenhauf P, Memish ZA. Covid-19 and community mitigation strategies in a pandemic. BMJ. 2020;368:m1066 https://doi.org/10.1136/bmj.m1066.

4. Matsushita K, Ding N, Kou M, Hu X, Chen M, Gao Y, et al. The relationship of COVID-19 severity with cardiovascular disease and its traditional risk factors: A systematic review and meta-analysis. medRxiv. 2020:20054155 https://doi. org/10.1101/2020.04.05.20054155.

5. Clark A, Jit M, Warren-Gash C, Guthrie B, Wang HHX, Mercer SW et al. How many are at increased risk of severe COVID-19 disease? Rapid global, regional and national estimates for 2020. https://cmmid.github.io/topics/ covid19/Global_risk_factors.html.

6. GBD 2017 Disease and Injury Incidence and Prevalence Collaborators. Global, regional, and national incidence, prevalence, and years lived with disability for 354 diseases and injuries for 195 countries and territories, 1990-2017: a systematic analysis for the Global Burden of Disease Study 2017. Lancet. 2018;392(10159):1789-858.

7. Brown GC. Living too long: the current focus of medical research on increasing the quantity, rather than the quality, of life is damaging our health and harming the economy. EMBO Rep. 2015;16(2):137-41.

8. Institute for Health Metrics and Evaluation. GBD Results Tool. Seattle: University of Washington; 2018. http://ghdx.healthdata.org/gbd-results-tool Accessed 10 Apr 2020

9. Institute for Health Metrics and Evaluation. GBD 2017 causes of disease and injuries. Seattle: University of Washington; 2018. http://www.healthdata.org/
sites/default/files/files/Projects/GBD/GBD_2017_heirarchies.zip Accessed 10 Apr 2020.

10. Public Health England. Guidance on social distancing for everyone in the UK. United Kingdom Government. https://www.gov.uk/government/ publications/covid-19-guidance-on-social-distancing-and-for-vulnerablepeople/guidance-on-social-distancing-for-everyone-in-the-uk-andprotecting-older-people-and-vulnerable-adults. Accessed 10 Apr 2020.

11. Lighter J, Phillips M, Hochman S, Sterling S, Johnson D, Francois F, et al. Obesity in patients younger than 60 years is a risk factor for Covid-19 hospital admission. Clin Infect Dis. 2020:ciaa415 https://doi.org/10.1093/cid/ ciaa415.

12. Fang $L$, Karakiulakis $G$, Roth $M$. Are patients with hypertension and diabetes mellitus at increased risk for COVID-19 infection? Lancet Respir Med. 2020; 8(4):e21 https://doi.org/10.1016/S2213-2600(20)30116-8.

13. Institute for Health Metrics and Evaluation. Global Health Data Exchange (GHDx). Seattle: University of Washington; 2020. http://ghdx.healthdata.org/ Accessed 10 Apr 2020

14. European Centre for Disease Prevention and Control. Data on the geographic distribution of COVID-19 cases worldwide: European Union, 2020. https://www.ecdc.europa.eu/en/publications-data/download-todaysdata-geographic-distribution-covid-19-cases-worldwide/. Accessed $28 \mathrm{Apr}$ 2020.

15. State Chancellery of the Republic of Latvia. Press releases. https://mk.gov.lv/ en/aktualitates/regarding-declation-emergency-situation. Accessed $28 \mathrm{Apr}$ 2020.

16. Republic of Estonia Government. The government declared an emergency situation in Estonia until 1 May. https://www.valitsus.ee/en/news/ government-declared-emergency-situation-estonia-until-1-may. Accessed 28 Apr 2020.

17. Steel N, Ford JA, Newton JN, Davis ACJ, Vos T, Naghavi M, et al. Changes in health in the countries of the UK and 150 English local authority areas 1990-2016: a systematic analysis for the global burden of disease study 2016. Lancet. 2018;392(10158):1647-61 https://doi.org/10.1016/S01406736(18)32207-4.

18. Wyper GMA, Grant I, Fletcher E, McCartney G, Stockton DL. The impact of worldwide, national and sub-national severity distributions in burden of disease studies: a case study of cancers in Scotland. PLoS One. 2019;14(8): e0221026 https://doi.org/10.1371/journal.pone.0221026.

19. Wyper GMA, Grant I, Fletcher E, Chalmers N, McCartney G, Stockton DL. Prioritising the development of severity distributions in burden of disease studies for countries in the European region. Arch Public Health. 2020;78(3) https://doi.org/10.1186/s13690-019-0385-6.

20. Global Burden of Disease Collaborative Network. Global Burden of Disease Study 2016 (GBD 2016) Disability Weights. Seattle: United States: Institute for Health Metrics and Evaluation (IHME); 2017.

\section{Publisher's Note}

Springer Nature remains neutral with regard to jurisdictional claims in published maps and institutional affiliations.

Ready to submit your research? Choose BMC and benefit from:

- fast, convenient online submission

- thorough peer review by experienced researchers in your field

- rapid publication on acceptance

- support for research data, including large and complex data types

- gold Open Access which fosters wider collaboration and increased citations

- maximum visibility for your research: over $100 \mathrm{M}$ website views per year

At BMC, research is always in progress.

Learn more biomedcentral.com/submissions 